\title{
Hypoxia-inducible factor-I $\alpha$ gene polymorphisms and cancer risk: a meta-analysis
}

\author{
Tongfeng Zhao*1, Jing Lv', Jiangpei Zhao ${ }^{2}$ and Marius Nzekebaloudou ${ }^{3}$
}

Address: ${ }^{1}$ Department of Geriatrics, the Second Affiliated Hospital, School of Medicine, Zhejiang University, 310009 Hangzhou, China, 2Department of Geriatrics, Hangzhou Hospital of Traditional Chinese Medicine, Hangzhou, China and ${ }^{3}$ Department of Food Science Nutrition, Zhejiang University, Hangzhou, China

Email: Tongfeng Zhao* - zhaotongfeng@yahoo.com.cn; Jing Lv - taimei1008@gmail.com; Jiangpei Zhao - zhaojiangpei1234@yahoo.com.cn; Marius Nzekebaloudou - nzekema@hotmail.com

* Corresponding author

Published: 27 December 2009

Journal of Experimental \& Clinical Cancer Research 2009, 28:159 doi:10.1186/1756-9966-28-159

This article is available from: http://www.jeccr.com/content/28/I/I59

(c) 2009 Zhao et al; licensee BioMed Central Ltd.

This is an Open Access article distributed under the terms of the Creative Commons Attribution License (http://creativecommons.org/licenses/by/2.0), which permits unrestricted use, distribution, and reproduction in any medium, provided the original work is properly cited.
Received: 8 November 2009

Accepted: 27 December 2009

\begin{abstract}
Background: The results from the published studies on the association between hypoxia-inducible factor -I (HIF-I $\alpha$ ) polymorphisms and cancer risk are conflicting. In this meta-analysis, we aimed to investigate the association between HIF-I $1772 \mathrm{C} / \mathrm{T}$ and $1790 \mathrm{G} / \mathrm{A}$ polymorphisms and cancer.
\end{abstract}

Methods: The meta-analysis for $1772 \mathrm{C} / \mathrm{T}$ polymorphism included $4 \mathrm{I} 3 \mathrm{I}$ cancer cases and 5387 controls, and for $1790 \mathrm{G} / \mathrm{A}$ polymorphism included 2058 cancer cases and 3026 controls. Allelic and genotypic comparisons between cases and controls were evaluated. Subgroup analyses by cancer types, ethnicity, and gender were also performed. We included prostate cancer in male subgroup, and female specific cancers in female subgroup.

Results: For the $1772 \mathrm{C} / \mathrm{T}$ polymorphism, the analysis showed that the $\mathrm{T}$ allele and genotype TT were significantly associated with higher cancer risk: odds ratio $(O R)=1.29[95 \%$ confidence interval $(\mathrm{Cl}, \mathrm{I} .0 \mathrm{I}, \mathrm{I} .65)], \mathrm{P}=0.04, \mathrm{P}_{\text {heterogeneity }}<0.0000 \mathrm{I}$, and $\mathrm{OR}=2.18[95 \% \mathrm{Cl}(\mathrm{I} .32,3.62)], \mathrm{P}=$ $0.003, P_{\text {heterogeneity }}=0.02$, respectively. The effect of the genotype TT on cancer especially exists in Caucasians and female subjects: $\mathrm{OR}=2.40[95 \% \mathrm{Cl}(\mathrm{I} .26,4.59)], \mathrm{P}=0.008, \mathrm{P}_{\text {heterogeneity }}=0.02$, and $\mathrm{OR}=3.60[95 \% \mathrm{Cl}(\mathrm{I} .17, \mathrm{II} . \mathrm{II})], \mathrm{P}=0.03, \mathrm{P}_{\text {heterogeneity }}=0.02$, respectively. For the $1790 \mathrm{G} / \mathrm{A}$ polymorphism, the pooled ORs for allelic frequency comparison and dominant model comparison suggested a significant association of $1790 \mathrm{G} / \mathrm{A}$ polymorphism with a decreased breast cancer risk: $\mathrm{OR}=0.28[95 \% \mathrm{Cl}(0.08,0.90)], \mathrm{P}=0.03, \mathrm{P}_{\text {heterogeneity }}=0.45$, and $\mathrm{OR}=0.29[95 \% \mathrm{Cl}(0.09,0.97)]$, $P=0.04, P_{\text {heterogeneity }}=0.4 \mathrm{I}$, respectively. The frequency of the HIF-I $1790 \mathrm{~A}$ allele was very low and only two studies were included in the breast cancer subgroup.

Conclusions: Our meta-analysis suggests that the HIF-I $1772 \mathrm{C} / \mathrm{T}$ polymorphism is significantly associated with higher cancer risk, and $1790 \mathrm{G} / \mathrm{A}$ polymorphism is significantly associated with decreased breast cancer risk. The effect of the $1772 \mathrm{C} / T$ polymorphism on cancer especially exists in Caucasians and female subjects. Only female specific cancers were included in female subgroup, which indicates that the $1772 \mathrm{C} / \mathrm{T}$ polymorphism is significantly associated with an increased risk for female specific cancers. The association between the $1790 \mathrm{G} / \mathrm{A}$ polymorphism and lower breast cancer risk could be due to chance. 


\section{Background}

Cancer is one of the leading causes of death in the world. It has become a worldwide public health problem [1]. The exact mechanism of carcinogenesis is not yet fully elucidated [2]. Recently, it has become clear that genetic variation contributes to the development and progression of cancer $[2,3]$. However, due to various reasons, including considerable heterogeneity of the disease, the identification of susceptibility genes is difficult and most associations have not been replicated.

Intratumoral hypoxia is a hallmark of solid cancer [4]. A hypoxic microenvironment initiates multiple cellular responses, such as proliferation and angiogenesis, resulting in the development and progression of cancer [4]. Hypoxia-inducible factor -1 (HIF-1) is a key transcription factor that regulates cellular response to hypoxia $[5,6]$. Studies have demonstrated that HIF-1 plays important roles in the development and progression of cancer through activation of various genes that are involved in crucial aspects of cancer biology, including angiogenesis, energy metabolism, vasomotor function, erythropoiesis, and cell survival $[5,6]$. HIF- 1 is a heterodimeric transcription factor consisting of $\alpha$ and $\beta$ subunits $[5,6]$. The $\beta$ subunit is constitutively expressed and the $\alpha$ subunit which determines HIF-1 activity is regulated by oxygen tension. Hypoxia- inducible factor $-1 \alpha$ (HIF- $1 \alpha$ ) is hydroxylated and degraded rapidly under normoxic conditions through von Hippel-Lindau mediated ubiquitin-proteasome pathway whereas it becomes stabilized and is rapidly accumulated in cell under hypoxic conditions $[5,6]$. Recent studies have shown overexpression of HIF- $1 \alpha$ in many human cancers with an advanced tumor grade, implying HIF-1 $\alpha$ as an independent prognostic factor of cancer [7].

HIF-1 gene polymorphisms have been investigated for a possible role in mediating genetic predisposition to cancer [8]. Recently, two single nucleotide polymorphisms (SNPs) of human HIF-1 gene, HIF-1 $1772 \mathrm{C} / \mathrm{T}$ (rs11549465) and 1790 G/A (rs rs11549467), which result in proline to serine and alanine to threonine amino acid substitutions, respectively, were identified. Both of them are located within exon 12 of the HIF-1 gene $[5,6]$. The presences of these polymorphic variants were shown to cause a significantly higher transcriptional activity than the activity of the wild type in vitro studies under both normoxic and hypoxic conditions [5,6]. Moreover, both of the polymorphisms were associated with increased tumor microvessel density, thus contributing to the development and progression of cancer [5,6]. A number of investigators have studied the possible association between the HIF-1 polymorphisms and cancer risk, but the results have been conflicting [5,6,8-22]. Thus, the association between the HIF-1 $1772 \mathrm{C} / \mathrm{T}$ and $1790 \mathrm{G} / \mathrm{A}$ polymorphisms and cancer requires further investigation.
In this paper, a meta-analysis was performed on previous reports to investigate the association of HIF-1 $1772 \mathrm{C} / \mathrm{T}$ and $1790 \mathrm{G} /$ A polymorphism with cancer.

\section{Materials and methods Identification and eligibility of relevant studies}

All studied published before June 2009 that investigated the association between the HIF-1 1772 C/T and $1790 \mathrm{G} /$ A polymorphisms with cancer were considered in the meta-analysis. A systematic search of the literature was carried out by using PubMed. The language was limited to English. The keywords used for this search were "HIF-1 OR hypoxia-inducible factor-1" concatenated with "polymorphism OR variant OR SNP OR mutation" AND "cancer OR tumor OR carcinoma OR malignancy". Only the studies with complete data on comparison of frequency of the HIF-1 $1772 \mathrm{C} / \mathrm{T}$ and $1790 \mathrm{G} /$ A gene polymorphisms between controls and patients with cancer were selected. Animal studies, case reports, review articles, abstracts, editorials, reports with incomplete data, and studies based on pedigree data were excluded.

\section{Data extraction}

Two investigators independently reviewed the articles to exclude irrelevant and overlapping studies. The results were compared, and disagreements were resolved by discussion and consensus. When overlapping articles were found, we only included the publication that reported the most extensive information. From each study, the following information was extracted: journal, year of publication, first author, demographics, racial background of the study population, validity of the genotyping method, matching, and the number of cases and controls for each genotype. Frequencies of alleles were calculated for the cases and the controls, from the corresponding genotype distributions.

\section{Statistical analysis}

Review Manager 5.0 software (The Cochrane Collaboration, Oxford, UK) was used for meta-analysis. The following genotype contrasts for the HIF-1 1772 C/T polymorphism were evaluated: homozygotes TT versus a combination of CT and CC [TT versus $(\mathrm{CT}+\mathrm{CC})$, recessive model], a combination of TT and CT versus CC [(TT+CT) versus $\mathrm{CC}$, dominant model]. Contrast of $\mathrm{C}$ allelic frequency versus $G$ allelic frequency ( $C$ versus $G$ ) was also evaluated. A allele of the HIF-1 $1790 \mathrm{G} / \mathrm{A}$ polymorphism was very rare. In most of the studies, homozygote AA was totally absent in both case and controls. For the HIF-1 $1790 \mathrm{G} / \mathrm{A}$ polymorphism, we only performed allelic frequency comparison (A versus $G$ ) and dominant model comparison [(AA+AG) versus $G G]$. In addition, we conducted subgroup analyses by cancer types, ethnicity, and gender. For gender subgroups, we included prostate cancer in male subgroup, and female specific cancers such as 
breast cancer, endometrial cancer, ovarian cancer and cervix cancer in female subgroup. We only conducted the meta-analysis on the subgroup with more than two studies in Hardy-Weinberg equilibrium (HWE). For the HIF-1 $1790 \mathrm{G} /$ A polymorphism, the pooled effects for other cancers (exclusion of the study on breast cancer) were also performed.

The existence of heterogeneity between studies was ascertained by Q-statistic. The pooled odds ratio (OR) was estimated with models based on fixed effects or random effects assumptions. If the significant $Q$ statistic $(P<0.1)$ indicated heterogeneity across studies, a random effects model was used for meta-analysis. Otherwise, a fixed effect model was selected. The $95 \%$ confidence interval (CI) of OR was also calculated. The distributions of genotypes in the controls were checked for HWE. Studies with the controls not in HWE were subjected to a sensitivity analysis [23].

The publication bias among the studies from the cases versus controls was assayed. Funnel plots of the HIF-1 1772 $\mathrm{C} / \mathrm{T}$ polymorphism for T versus $\mathrm{C}$ and HIF-1 $1790 \mathrm{G} / \mathrm{A}$ polymorphism for A versus $\mathrm{G}$ were performed to look for evidence of publication bias. The funnel plot should be asymmetric when there is publication bias and symmetric in the case of no publication bias. Egger's test, estimated by MIX 1.7 software (Kitasato Clinical Research Center, Kitasato University, Japan), was performed to measure the funnel plot asymmetry [24-26].

\section{Results \\ Eligible studies}

The flow diagram illustrates the main reasons for studies exclusion (Additional file 1). The selected study characteristics were summarized in Additional file 2. 16 relevant case-control studies concerning the HIF-1 $1790 \mathrm{G} / \mathrm{A}$ and $1772 \mathrm{C} / \mathrm{T}$ polymorphisms and cancer were included in the meta-analysis. In all 16 studies, there were 9 studies of Caucasians, 5 studies of East Asians, 2 studies of mixed ethnicity. The 16 studies included 4 studies on prostate cancer, 3 studies on breast cancer, 2 studies on colorectal carcinoma, 2 studies on renal cell carcinoma, 1 studies on endometrial cancer, 1 study on early stage of oral squamous cell carcinoma, 1 study on ovarian cancer, endometrial cancer, and cervical cancer, 1 study on esophageal squamous cell carcinoma, and 1 study on head and neck squamous cell carcinoma. The samples only consisted of females in 7 studies, only consisted of males in 4 studies, and consisted of both females and males in 5 studies. In the eligible studies, all the 16 studies presented the data on the $1772 \mathrm{C} / \mathrm{T}$ polymorphism, 10 studies presented the data on the $1790 \mathrm{G} / \mathrm{A}$ polymorphism. For the $1772 \mathrm{C} / \mathrm{T}$ polymorphism, the distributions of the genotypes in the control groups in 5 studies were not in HWE. For the 1790
G/A polymorphism, the distributions of the genotypes in control groups in 1 study were not in HWE. In all the eligible studies, 1 study provided data on three kinds of cancers (endometrial cancer, ovarian cancer, and cervical cancer) and both of the polymorphisms. Thus, each type of cancer in the study was treated as a separate study in this meta-analysis. In the eligible studies, 7 studies stated that the age, gender status or other variables were matched between the cases and controls, 1 paper just stated the controls were matched within constraints and did not describe the variables in detail, and 8 studies did not clearly state the use of a matching design for cases during the selection process of controls. Genotyping methods used in the eligible studies included PCR-restriction fragment length polymorphism (PCR-RFLP), direct sequencing, PCR-single strand conformational polymorphism (PCR-SSCP), and SNP-IT ${ }^{\mathrm{TM}}$ assays. Only 11 studies mentioned quality control of the genotyping, such as blindness to the case-control status, random repeat, or validation using a different genotyping method. The genotype and allele distribution of the HIF-1 $1772 \mathrm{C} / \mathrm{T}$ and $1790 \mathrm{G} / \mathrm{A}$ polymorphisms of individual studies were summarized in Additional file 3.

\section{Summary statistics}

The meta-analysis for the HIF-1 $1772 \mathrm{C} / \mathrm{T}$ polymorphism included 4131 cancer cases and 5387 controls. In both case group and control group, allele $\mathrm{C}$ was the most frequent, and the prevalence of the CC genotype was the highest, whilst the prevalence of the TT genotype was the lowest (Additional file 2, 3).

The meta-analysis for the HIF-1 $1790 \mathrm{G} /$ A polymorphism included 2058 cancer cases and 3026 controls. In both case group and control group, allele $\mathrm{G}$ was the most frequent, and the prevalence of the GG genotype was the highest, whilst the prevalence of the AA genotype was the lowest (Additional file 2, 3).

\section{Association of the HIF-I 1772 C/T polymorphism with cancer risk}

We first performed the meta-analysis on all 18 studies. The pooled ORs for allelic frequency comparison and recessive model comparison suggested that the $\mathrm{T}$ allele and genotype TT were significantly associated with an increased cancer risk: $\mathrm{OR}=1.29[95 \% \mathrm{CI}(1.01,1.65)], \mathrm{P}$ $=0.04, \mathrm{P}_{\text {heterogeneity }}<0.00001$, and $\mathrm{OR}=2.18[95 \% \mathrm{CI}$ $(1.32,3.62)], P=0.003, P_{\text {heterogeneity }}=0.02$, respectively (Table 1, Figure 1). We then performed the subgroup analyses stratified by cancer types, ethnicity and gender. The pooled ORs for allelic frequency comparison and dominant model comparison suggested the $1772 \mathrm{C} / \mathrm{T}$ polymorphism was significantly associated with an increased prostate cancer risk: $\mathrm{OR}=1.78[95 \% \mathrm{CI}(1.07,2.94)], \mathrm{P}=$ 0.03, $\mathrm{P}_{\text {heterogeneity }}<0.0001$, and $\mathrm{OR}=1.85[95 \%$ CI $(1.04$, 
Table I: Meta-analysis of the HIF-I $\alpha 1772 \mathrm{C} / \mathrm{T}$ polymorphism and cancer association.

\begin{tabular}{|c|c|c|c|c|c|c|}
\hline Genetic contrasts & $\begin{array}{l}\text { Group and subgroups } \\
\text { under analysis }\end{array}$ & Studies (n) & $\begin{array}{l}Q \text { test } \\
P \text { value }\end{array}$ & $\begin{array}{l}\text { Model } \\
\text { seclected }\end{array}$ & $\begin{array}{l}\text { OR } \\
(95 \% \mathrm{CI})\end{array}$ & $P$ \\
\hline \multirow[t]{11}{*}{$\mathrm{T}$ versus $\mathrm{C}$} & Overall & 18 & $<0.00001$ & Random & $1.29(1.01,1.65)$ & 0.04 \\
\hline & Overall in HWE & 13 & $<0.00001$ & Random & $1.39(1.02,1.90)$ & 0.04 \\
\hline & Caucasian & $\mathrm{II}$ & $<0.00001$ & Random & $1.33(0.90,1.97)$ & 0.15 \\
\hline & Caucasian in HWE & 7 & $<0.00001$ & Random & $1.69(0.94,3.04)$ & 0.08 \\
\hline & East Asian & 5 & 0.16 & Fixed & $\mathrm{I} .05(0.84,1.30)$ & 0.69 \\
\hline & Female* & 7 & $<0.00001$ & Random & $1.39(0.83,2.35)$ & 0.21 \\
\hline & Female in HWE* & 6 & $<0.00001$ & Random & $\mathrm{I} .48(0.8 \mathrm{I}, 2.7 \mathrm{I})$ & 0.20 \\
\hline & Male (prostate cancer) ${ }^{* *}$ & 4 & $<0.0001$ & Random & I.78 (I.07, 2.94) & 0.03 \\
\hline & $\begin{array}{l}\text { Male (prostate cancer) } \\
\text { in HWE** }\end{array}$ & 3 & $<0.0001$ & Random & $1.68(0.94,3.02)$ & 0.08 \\
\hline & Breast cancer & 3 & 0.12 & Fixed & $0.99(0.79,1.23)$ & 0.90 \\
\hline & Colorectal cancer & 2 & 0.02 & Random & $0.26(0.01,6.38)$ & 0.41 \\
\hline \multirow[t]{11}{*}{$\mathrm{TT}$ versus $(\mathrm{CT}+\mathrm{CC})$} & Overall & 18 & 0.02 & Random & $2.18(1.32,3.62)$ & 0.003 \\
\hline & Overall in HWE & 13 & 0.002 & Random & $2.87(1.14,7.26)$ & 0.03 \\
\hline & Caucasian & II & 0.02 & Random & $2.40(1.26,4.59)$ & 0.008 \\
\hline & Caucasian in HWE & 7 & 0.01 & Random & 3.35 (1.01, II.1I) & 0.05 \\
\hline & East Asian & 5 & 0.76 & Fixed & $5.31(0.91,30.83)$ & 0.06 \\
\hline & Female* & 7 & 0.02 & Random & $3.60(1.17,11.11)$ & 0.03 \\
\hline & Female in HWE* & 6 & 0.01 & Random & $3.88(0.94,16.01)$ & 0.06 \\
\hline & Male (prostate cancer) ${ }^{* *}$ & 4 & 0.1 & Fixed & $\mathrm{I} .53(0.90,2.60)$ & 0.11 \\
\hline & $\begin{array}{l}\text { Male (prostate cancer) } \\
\text { in HWE** }\end{array}$ & 3 & 0.04 & Random & $1.78(0.4 \mathrm{I}, 7.74)$ & 0.44 \\
\hline & Breast cancer & 3 & 0.10 & Fixed & $1.5 \mathrm{I}(0.55,4.1 \mathrm{I})$ & 0.42 \\
\hline & Colorectal cancer & 2 & - & Random & $1.97(0.33,11.90)$ & 0.46 \\
\hline \multirow[t]{11}{*}{$(\mathrm{TT}+\mathrm{CT})$ versus $\mathrm{CC}$} & Overall & 18 & $<0.00001$ & Random & $1.19(0.88,1.59)$ & 0.26 \\
\hline & Overall in HWE & 13 & $<0.00001$ & Random & $\mathrm{I} .34(0.97, \mathrm{I} .85)$ & 0.08 \\
\hline & Caucasian & 11 & $<0.00001$ & Random & I.I5 (0.68, I.93) & 0.61 \\
\hline & Caucasian in HWE & 7 & $<0.00001$ & Random & $\mathrm{I} .70(0.89,3.26)$ & 0.11 \\
\hline & East Asian & 5 & 0.15 & Fixed & $1.01(0.80,1.27)$ & 0.96 \\
\hline & Female* & 7 & 0.0004 & Random & $1.28(0.76,2.15)$ & 0.35 \\
\hline & Female in $\mathrm{HWE}^{*}$ & 6 & 0.0002 & Random & I.4I $(0.77,2.57)$ & 0.26 \\
\hline & Male (prostate cancer) ${ }^{* *}$ & 4 & $<0.0001$ & Random & $\mathrm{I} .85(1.04,3.31)$ & 0.04 \\
\hline & $\begin{array}{l}\text { Male (prostate cancer) } \\
\text { in HWE** }\end{array}$ & 3 & $<0.0001$ & Random & $1.75(0.89,3.47)$ & 0.11 \\
\hline & Breast cancer & 3 & 0.22 & Fixed & $0.96(0.76,1.21)$ & 0.75 \\
\hline & Colorectal cancer & 2 & 0.02 & Random & $0.25(0.01,5.99)$ & 0.39 \\
\hline
\end{tabular}

OR, odds ratio; $\mathrm{Cl}$, confidence interval; HWE, Hardy-Weinberg equilibrium.

* Only female specific cancers were included in the female subgroup.

** All male patients were the patients with prostate cancer.

3.31)], $\mathrm{P}=0.04, \mathrm{P}_{\text {heterogeneity }}<0.0001$, respectively (Table 1). The association between the genotype TT and increased cancer susceptibility was significant in Caucasians and in female subjects: OR $=2.40$ [95\% CI $(1.26$, 4.59) $], \mathrm{P}=0.008, \mathrm{P}_{\text {heterogeneity }}=0.02$, and $\mathrm{OR}=3.60[95 \%$ CI $(1.17,11.11)], P=0.03, P_{\text {heterogeneity }}=0.02$ (Table 1, Figure 2, 3). A marginal significant association between the $1772 \mathrm{C} / \mathrm{T}$ polymorphism and increased cancer risk was detected in East Asians under recessive model: OR = $5.31[95 \%$ CI $(0.91,30.83)], P=0.06, P_{\text {heterogeneity }}=0.76$ (Table 1). The remaining pooled ORs from this analysis were not significant $(\mathrm{P}>0.05)$ (Table 1$)$.

Sensitivity analysis was next performed by excluding the studies with controls not in HWE. The results from the allelic frequency comparison and dominant model com- parison showed no evidence that the $1772 \mathrm{C} / \mathrm{T}$ polymorphism was significantly associated with an increased prostate cancer risk: $\mathrm{OR}=1.68[95 \% \mathrm{CI}(0.94,3.02)], \mathrm{P}=$ 0.08 , Pheterogeneity $<0.0001$, and $\mathrm{OR}=1.75[95 \% \mathrm{CI}$ $(0.89,3.47)], P=0.11$, Pheterogeneity $<0.0001$, respectively (Table 1). The association between the genotype TT and the increased cancer risk was marginally significant in Caucasians and in female subjects: OR $=3.35$ [95\% CI $(1.01,11.11)], P=0.05$, Pheterogeneity $=0.01$, and $\mathrm{OR}=$ 3.88 [95\% CI $(0.94,16.01)], \mathrm{P}=0.06$, Pheterogeneity $=$ 0.01 , respectively (Table 1 , Figure 2,3 ). The other results were similar to those when the studies with controls not in HWE were included (Table 1).

There was significant heterogeneity among the available studies (Table 1). To detect the source of the heterogene- 


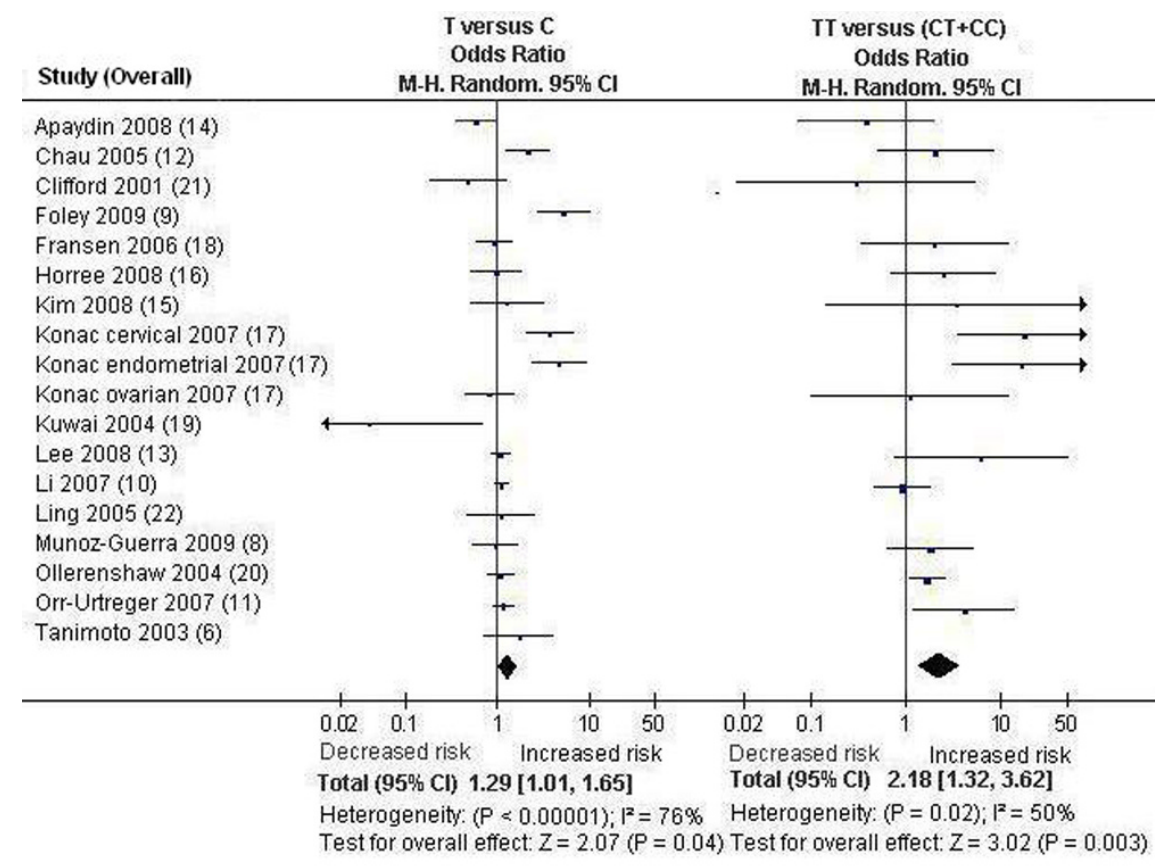

Figure I

Forest plot of the HIF-I $1772 \mathrm{C} / \mathrm{T}$ polymorphism and cancer risk [T versue $\mathrm{C}$ and TT versus (CT+CC)]. Results from the analysis on all available studies.

ity, we performed the subgroup analyses by gender, cancer types, and ethnicity. The results showed studies in female subject subgroup and Caucasian subgroup were the main contributors of heterogeneity (Table 1).

\section{Association of the HIF-I I 790 GIA polymorphism with cancer risk}

The results on all 12 studies showed no evidence that the HIF-1 1790 G/A polymorphism was significantly associated with an increased cancer risk $(\mathrm{P}>0.05)$ (Table 2, Figure 4 ). The significant association between the A allele and the increased cancer risk was detected in other cancers: $\mathrm{OR}=2.31$ [95\% CI $(1.12,4.75)], \mathrm{P}=0.02, \mathrm{P}_{\text {heterogene- }}$ ity $=0.0004$ (Table IV) (Table 2). A marginal association between the $1790 \mathrm{G} / \mathrm{A}$ polymorphism and the increased cancer risk in other cancers was also detected under dominant model: $\mathrm{OR}=2.22[95 \% \mathrm{CI}(0.95,5.20)], \mathrm{P}=0.06$, $\mathrm{P}_{\text {heterogeneity }}<0.00001$ (Table 2). The pooled ORs for allelic frequency comparison and dominant model comparison suggested the $1790 \mathrm{G} / \mathrm{A}$ polymorphism was significantly associated with an increased cancer risk in Caucasians: $\mathrm{OR}=3.08$ [95\% CI $(1.49,6.36)], \mathrm{P}=0.002$, $\mathrm{P}_{\text {heterogeneity }}=0.04$, and OR $=2.60[95 \%$ CI $(1.03,6.59)]$, $\mathrm{P}=0.04, \mathrm{P}_{\text {heterogeneity }}=0.002$, respectively (Table 2 ). However, reanalysis after exclusion the studies with controls not in HWE did not suggest these associations $(P>0.05)$ (Table 2). The pooled ORs for A versus $G$ and (AA+AG) versus GG suggested that $1790 \mathrm{G} / \mathrm{A}$ polymorphism was significantly associated with a decreased breast cancer risk:
$\mathrm{OR}=0.28[95 \% \mathrm{CI}(0.08,0.90)], \mathrm{P}=0.03, \mathrm{P}_{\text {heterogeneity }}=$ 0.45 , and OR $=0.29[95 \%$ CI $(0.09,0.97)], P=0.04, P_{\text {het }}$ erogeneity $=0.41$, respectively (Table 2, Figure 4 ). The remaining pooled ORs on the association of $1790 \mathrm{G} / \mathrm{A}$ polymorphism and cancer risk were not significant $(\mathrm{P}>$ 0.05) (Table 2).

There was significant heterogeneity for allelic frequency comparison and dominant model comparison among the available studies (Table 2). However, the heterogeneity was effectively decreased or removed in the subgroups stratified by gender, ethnicity, and cancer types (Table 2).

\section{Publication bias}

Publication bias was assayed by visual funnel plot inspection and Egger's test. The funnel plots for T versus $\mathrm{C}$ were basically symmetric (Additional file 4A) and Egger's test did not indicate asymmetry of the plot [Intercept = $0.5092,95 \%$ CI $(-1.5454,2.5639), P=0.6065]$. The funnel plots for A versus $G$ showed some asymmetry that could suggest the existence of publication bias (Additional file 4B). However, Egger's test did not show statistical evidence for publication bias [Intercept $=-1.82,95 \%$ CI $(-4.1611,0.5212), \mathrm{P}=0.1108]$.

\section{Discussion}

HIF-1 plays a major role in cancer progression and metastasis through activation of various genes that are linked to regulation of angiogenesis, cell survival, and energy 


\section{A} Study (Caucasian)

Odds Ratio

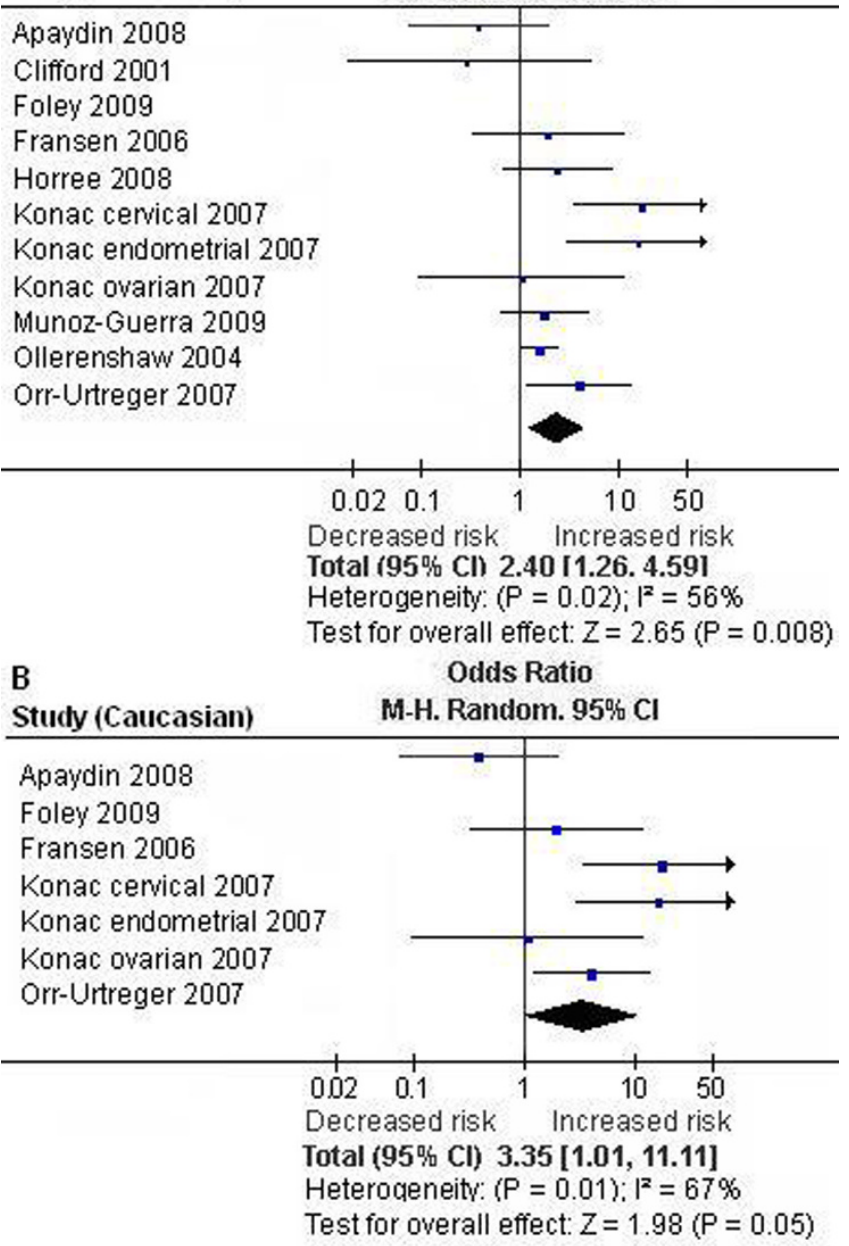

Figure 2

Forest plot the HIF-I $1772 \mathrm{C} / \mathrm{T}$ polymorphism and cancer risk in Caucasians [TT versus $(C T+C C)$ ]. $A$. Results from the analysis on all studies of Caucasians. $B$. Results from the sensitivity analysis (exclusion of the studies with controls not in Hardy-Weinberg equilibrium).

metabolism $[5,6]$. The HIF-1 gene was previously found to be implicated in the development and progression of cancer $[5,6]$. The polymorphisms analyzed in the present study consist of $\mathrm{C}$ to $\mathrm{T}$ and $\mathrm{G}$ to A nucleotide substitutions at positions 1772 and 1790 of the exon 12 of the HIF-1 gene $[5,6]$. Because a study by Tanimoto et al [6] showed that both of the substitutions displayed an increased transactivation capacity of HIF- $1 \alpha$ in vitro, the presence of the variant alleles might be associated with increased cancer susceptibility. However, studies focusing on the association of the HIF-1 gene polymorphism with cancer susceptibility had controversial conclusions [5,6,8-22]. The lack of concordance across many of these studies reflects limitation in the studies, such as small sample

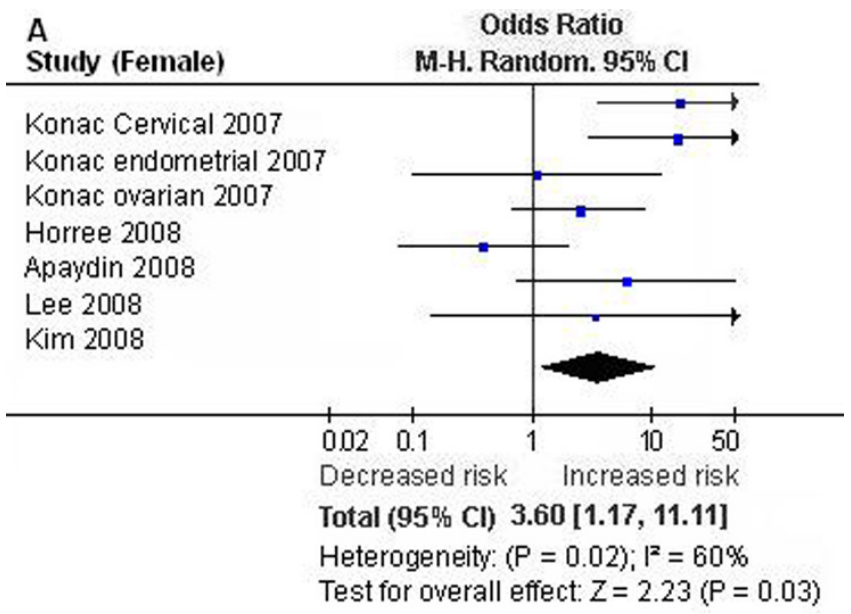

\section{B}

Study (Female)

Odds Ratio

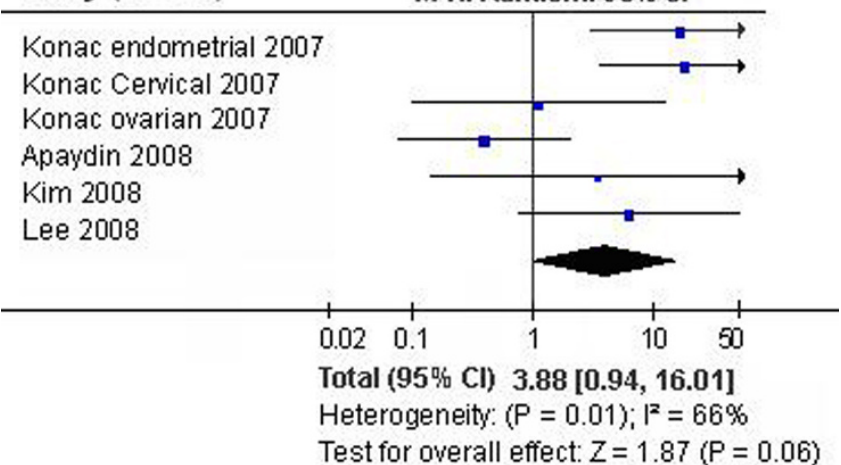

Figure 3

Forest plot the HIF-I I $772 \mathrm{C} / \mathrm{T}$ polymorphism and cancer risk in female subjects [TT versus $(C T+C C)$ ].

A. Results from the analysis on all studies of female subjects. B. Results from the sensitivity analysis (exclusion of the studies with controls not in Hardy-Weinberg equilibrium).

sizes, ethnic difference and research methodology. Metaanalysis is a powerful tool for summarizing the results from different studies by producing a single estimate of the major effect with enhanced precision. It can overcome the problem of small sample size and inadequate statistical power of genetic studies of complex traits, and provide more reliable results than a single case-control study [27].

In this meta-analysis, we investigated the association between the HIF-1 $1772 \mathrm{C} / \mathrm{T}$ and $1790 \mathrm{G} / \mathrm{A}$ polymorphism and cancer risk. The subgroup analyses stratified by cancer types, ethnicity, and gender were also performed. For the HIF-1 $1772 \mathrm{C} / \mathrm{T}$ polymorphism, our meta-analysis on the available studies showed that the $\mathrm{T}$ allele and genotype TT were significantly associated with increased cancer risk. These associations were very robust, which did not vary materially when the sensitivity analyses (exclusion the study with controls not in HWE) were performed. 
Table 2: Meta-analysis of the HIF-I 1790 G/A polymorphism and cancer association.

\begin{tabular}{|c|c|c|c|c|c|c|}
\hline $\begin{array}{l}\text { Genetic } \\
\text { contrasts }\end{array}$ & $\begin{array}{l}\text { Group and subgroups } \\
\text { under analysis }\end{array}$ & $\begin{array}{l}\text { Studies } \\
\text { (n) }\end{array}$ & $\begin{array}{l}Q \text { test } \\
P \text { value }\end{array}$ & $\begin{array}{l}\text { Model } \\
\text { seclected }\end{array}$ & $\begin{array}{l}\text { OR } \\
(95 \% \mathrm{CI})\end{array}$ & $P$ \\
\hline \multirow[t]{10}{*}{$A$ versus $G$} & Overall & 12 & $<0.00001$ & Random & I.6I $(0.75,3.45)$ & 0.22 \\
\hline & Overall in HWE & II & 0.0002 & Random & $1.32(0.54,3.24)$ & 0.54 \\
\hline & Caucasian & 9 & 0.04 & Random & $3.08(1.49,6.36)$ & 0.002 \\
\hline & Caucasian in HWE & 8 & 0.02 & Random & $2.15(0.66,7.02)$ & 0.20 \\
\hline & East Asian & 2 & 0.33 & Fixed & $0.58(0.24,1.40)$ & 0.23 \\
\hline & Female* & 5 & 0.07 & Random & $0.65(0.07,6.05)$ & 0.71 \\
\hline & Male (prostate cancer) ${ }^{* *}$ & 2 & 0.64 & Fixed & $0.96(0.49,1.90)$ & 0.91 \\
\hline & Breast cancer & 2 & 0.45 & Fixed & $0.28(0.08,0.90)$ & 0.03 \\
\hline & Other cancers & 10 & 0.0004 & Random & $2.31(1.12,4.75)$ & 0.02 \\
\hline & Other cancers in HWE & 9 & 0.002 & Random & $1.97(0.79,4.90)$ & 0.15 \\
\hline \multirow[t]{10}{*}{$(A A+A G)$ versus $G G$} & Overall & 12 & $<0.00001$ & Random & $1.56(0.66,3.65)$ & 0.31 \\
\hline & Overall in HWE & II & 0.0004 & Random & $1.25(0.53,2.97)$ & 0.61 \\
\hline & Caucasian & 9 & 0.002 & Random & $2.60(1.03,6.59)$ & 0.04 \\
\hline & Caucasian in HWE & 8 & 0.004 & Random & $1.80(0.50,6.54)$ & 0.37 \\
\hline & East Asian & 2 & 0.41 & Fixed & $0.61(0.25,1.51)$ & 0.29 \\
\hline & Female* & 5 & 0.08 & Random & $0.68(0.07,6.30)$ & 0.74 \\
\hline & Male (prostate cancer) $* *$ & 2 & 0.64 & Fixed & $0.96(0.49,1.90)$ & 0.91 \\
\hline & Breast cancer & 2 & 0.41 & Fixed & $0.29(0.09,0.97)$ & 0.04 \\
\hline & Other cancers & 10 & $<0.00001$ & Random & $2.22(0.95,5.20)$ & 0.06 \\
\hline & Other cancers in HWE & 9 & 0.002 & Random & $\mathrm{I} .78(0.72,4.43)$ & 0.21 \\
\hline
\end{tabular}

OR, odds ratio; $\mathrm{Cl}$, confidence interval; HWE, Hardy-Weinberg equilibrium.

* Only female specific cancers were included in the female subgroup.

** All male patients were the patients with prostate cancer

The effect of the genotype TT on cancer especially exists in Caucasians and female subjects. Only female specific cancers were included in female subgroup in our meta-analysis, which indicates that the genotype TT is significantly associated with an increased risk for female specific cancers. The molecular basis of gender specific effect of the HIF-1 $1772 \mathrm{C} / \mathrm{T}$ polymorphism on cancers is unclear. Studies have shown that estrogen can induce the expression of HIF-1 [28,29]. The substitution of $\mathrm{C}$ to $\mathrm{T}$ at positions 1772 of the exon 12 of the HIF-1 gene further increase the transactivation capacity of the HIF-1 gene and thus promote the development of female specific cancers. We also observed a marginally significant association between the genotype TT and increased cancer risk in East Asians. However, subjects with mutant homozygotes were only detected in two studies of East Asians. The CI for this subgroup was very wide, and the association could have been caused by chance. More studies based on larger population should be conducted to further examine this association.

For the HIF-1 $1790 \mathrm{G} / \mathrm{A}$ polymorphism, the meta-analysis on all studies showed no evidence that the HIF-1 1790 G/A polymorphism was significantly associated with increased cancer risk. We also performed the stratification analyses by gender, ethnicity, and cancer types. The pooled ORs for allelic frequency comparison and dominant model comparison suggested the $1790 \mathrm{G} / \mathrm{A}$ polymorphism was significantly associated with an increased cancer risk in Caucasians. However, the sensitivity analysis did not suggest this association. Because the results from the sensitivity analysis were more valid, our metaanalysis does not strongly suggest the association between the HIF-1 $1790 \mathrm{G} / \mathrm{A}$ polymorphism and cancer risk in Caucasians [23]. The pooled effects for allelic frequency comparison and dominant model comparison suggested a significant association between the HIF-1 1790 G/A polymorphism and a decreased breast cancer risk. Because the conclusion is inconsistent with the general understanding that the 1790 A alleles enhances HIF-1 transcriptional activity and the presence of the variant allele might be associated with increased cancer susceptibility, we further performed the meta-analysis for the other cancers to detect the specific effects of cancer type [6]. The results suggested a significant association between the A allele and increased cancer risk in other cancers. A marginal association between the $1790 \mathrm{G} / \mathrm{A}$ polymorphism and increased cancer risk in other cancers was also detected under dominant model. However, the reanalysis after exclusion the studies with controls not in HWE did not suggest these associations. Our meta-analysis does not strongly support the association between the HIF-1 1790 $\mathrm{G} / \mathrm{A}$ polymorphism and the cancer risk in other cancers. The exact mechanism for the inverse association between the HIF-1 $1790 \mathrm{G} / \mathrm{A}$ polymorphism and breast cancer was not clear. However, there were two factors that must be considered. First, the frequency of the HIF-1 1790 A allele was very low and only two studies were included in the 


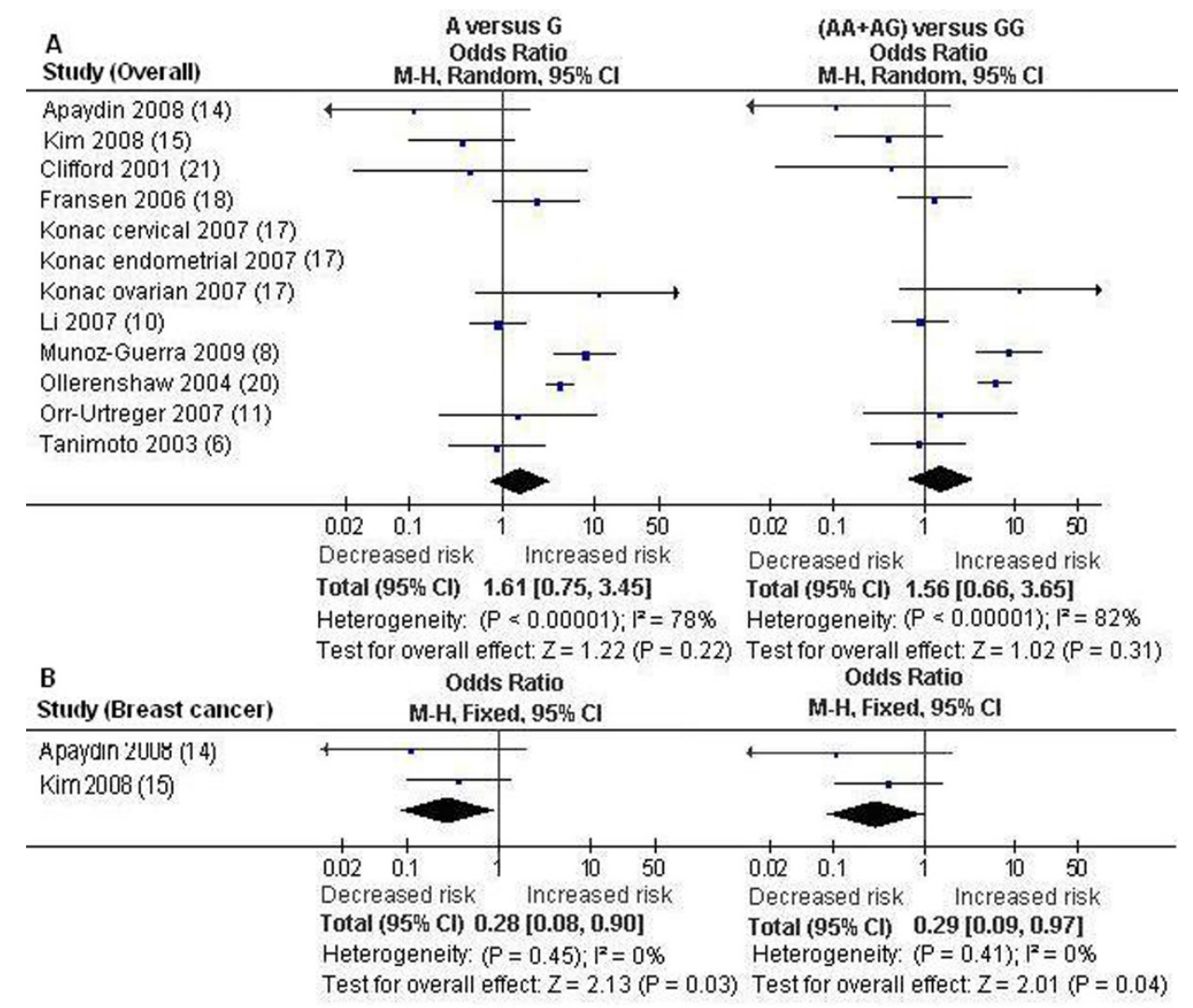

\section{Figure 4}

Forest plot the HIF-I 1790 G/A polymorphism and cancer risk [A versue $G$ and (AA+AG) versus GG]. A. Results from the analysis on all available studies. B. Results from the analysis on breast cancer subgroup.

breast cancer subgroup. So, the association could be due to chance. Second, our meta-analysis suggests that carcinogenic mechanism may differ in different cancers and HIF-1 1790 G/A polymorphism may exert varying effect. More studies will be required to further examine the association.

The current meta-analysis has several limitations which should be noted. First, the meta-analysis was based on the aggregation of published case-control studies. 8 studies did not clearly state the use of a matching design for cases during the selection process of controls. The meta-analysis was based on unadjusted estimates. A more precise analysis should be conducted if more detailed individual data were available, which would allow for an adjusted estimate. Second, because of data limitation, we did not perform the stratification analyses by age, smoking, or other variables. Third, several genotyping methods were used in the eligible studies. The quality control of genotyping was not well documented in some studies. Undoubtedly, the limitations mentioned should affect our final conclusions.

\section{Conclusions}

Our meta-analysis suggests that the HIF-1 $1772 \mathrm{C} / \mathrm{T}$ polymorphism is significantly associated with higher cancer risk, and the $1790 \mathrm{G} / \mathrm{A}$ polymorphism is significantly associated with decreased breast cancer risk. The effect of the $1772 \mathrm{C} / \mathrm{T}$ polymorphism on cancer especially exists in Caucasians and female subjects. Only female specific cancers were included in female subgroup, which indicates that the $1772 \mathrm{C} / \mathrm{T}$ polymorphism is significantly associated with an increased risk for female specific cancers. The association between the $1790 \mathrm{G} / \mathrm{A}$ polymorphism and lower breast cancer risk could be due to chance.

\section{Abbreviations}

CI: confidence interval; HWE: Hardy-Weinberg equilibrium; HIF-1: hypoxia- inducible factor -1 ; HIF-1 $\alpha$ : hypoxia- inducible factor $-1 \alpha$; OR: odds ratio; SNP: single nucleotide polymorphism.

\section{Competing interests}

The authors declare that they have no competing interests. 


\section{Authors' contributions}

TFZ participated in the design, data acquisition, manuscript writing, and have given final approval of the version to be published. JPZ performed data analysis, data interpretation. JL participated in the design, data acquisition. $\mathrm{MN}$ participated in data analysis and drafting the manuscript. All authors read and approved the final manuscript.

\section{Additional material}

\section{Additional file 1}

The flow diagram of included/excluded studies.

Click here for file

[http://www.biomedcentral.com/content/supplementary/17569966-28-159-S1.JPEG]

\section{Additional file 2}

Characteristics of individual studies included in the meta-analysis. Click here for file

[http://www.biomedcentral.com/content/supplementary/17569966-28-159-S2.DOC]

\section{Additional file 3}

Genotype and allele distribution of hypoxia- inducible factor $-1 \alpha$ $1772 \mathrm{C} / \mathrm{T}$ and $1790 \mathrm{G} / \mathrm{A}$ polymorphisms of individual studies included in the meta-analysis.

Click here for file

[http://www.biomedcentral.com/content/supplementary/17569966-28-159-S3.DOC]

\section{Additional file 4}

Funnel plots for publication bias test. A. HIF- $1 \alpha 1772 \mathrm{C} / \mathrm{T}$ : T versus $C$. $B$. HIF-1 11790 G/A: A versus G. Each point represents a separate study for the indicated association. SE(SMD), standard error of the logarithm of the odd ratio.

Click here for file

[http://www.biomedcentral.com/content/supplementary/17569966-28-159-S4.JPEG]

\section{Acknowledgements}

This work was supported by National Natural Science foundation of China (Grant No: 30671007) and Natural Science foundation of Zhejiang Province, China (Grant No: Y208IIII).

\section{References}

I. Jemal A, Siegel R, Ward E, Hao Y, Xu J, Thun MJ: Cancer statistics, 2009. CA Cancer I Clin 2009, 59(4):225-249.

2. Wright ME, Peters U, Gunter MJ, Moore SC, Lawson KA, Yeager M, Weinstein SJ, Snyder K, Virtamo J, Albanes D: Association of variants in two vitamin e transport genes with circulating vitamin e concentrations and prostate cancer risk. Cancer Res 2009, 69(4): 1429-1438.

3. Cheung WY, Liu G: Genetic variations in esophageal cancer risk and prognosis. Gastroenterol Clin North Am 2009, 38(I):75-9I.

4. Hill RP, Marie-Egyptienne DT, Hedley DW: Cancer stem cells, hypoxia and metastasis. Semin Radiat Oncol 2009, 19(2): I06- III.

5. Smaldone MC, Maranchie JK: Clinical implications of hypoxia inducible factor in renal cell carcinoma. Urol Oncol 2009 , 27(3):238-245.
6. Tanimoto K, Yoshiga K, Eguchi H, Kaneyasu M, Ukon K, Kumazaki T, Oue N, Yasui W, Imai K, Nakachi K, Poellinger L, Nishiyama M: Hypoxia-inducible factor-Ialpha polymorphisms associated with enhanced transactivation capacity, implying clinical significance. Carcinogenesis 2003, 24:1779-1783.

7. Zhong H, De Marzo AM, Laughner E, Lim M, Hilton DA, Zagzag D: Overexpression of hypoxia-inducible factor I alpha in common human cancers and their metastases. Cancer Res 1999, 59:5830-5835.

8. Munoz-Guerra MF, Fernandez-Contreras ME, Moreno AL, Martin ID, Herraez B, Gamallo C: Polymorphisms in the hypoxia inducible factor I-alpha and the impact on the prognosis of early stages of oral cancer. Ann Surg Oncol 2009, 16(8):235I-2358.

9. Foley R, Marignol L, Thomas AZ, Cullen IM, Perry AS, Tewari P, O'Grady A, Kay E, Dunne B, Loftus B, Watson WR, Fitzpatrick JM, Woodson K, Lehman T, Hollywood D, Lynch TH, Lawler M: The HIF-I $\alpha$ CI772T polymorphism may be associated with susceptibility to clinically localised prostate cancer but not with elevated expression of hypoxic biomarkers. Cancer Biol Ther 2009, 8(2): I | 8- I 24.

10. Li H, Bubley GJ, Balk SP, Gaziano JM, Pollak M, Stampfer MJ, Ma J: Hypoxia-inducible factor-I alpha (HIF-I alpha) gene polymorphisms, circulating insulin-like growth factor binding protein (IGFBP)-3 levels and prostate cancer. Prostate 2007, 67(12): 1354-1361.

II. Orr-Urtreger A, Bar-Shira A, Matzkin H, Mabjeesh NJ: The homozygous P582S mutation in the oxygen-dependent degradation domain of HIF-I alpha is associated with increased risk for prostate cancer. Prostate 2007, 67(I):8-I3.

12. Chau CH, Permenter MG, Steinberg SM, Retter AS, Dahut WL, Price DK, Figg WD: Polymorphism in the hypoxia-inducible factor I alpha gene may confer susceptibility to androgen-independent prostate cancer. Cancer Biol Ther 2005, 4(II):I222-I225.

13. Lee JY, Choi JY, Lee KM, Park SK, Han SH, Noh DY, Ahn SH, Kim DH, Hong YC, Ha E, Yoo KY, Ambrosone CB, Kang D: Rare variant of hypoxia-inducible factor-I alpha (HIF-IA) and breast cancer risk in Korean women. Clin Chim Acta 2008, 389(I-2): 167-I70.

14. Apaydin I, Konac E, Onen HI, Akbaba M, Tekin E, Ekmekci A: Single nucleotide polymorphisms in the hypoxia-inducible factorIalpha (HIF-Ialpha) gene in human sporadic breast cancer. Arch Med Res 2008, 39(3):338-345.

15. Kim HO, Jo YH, Lee J, Lee SS, Yoon KS: The CI772T genetic polymorphism in human HIF-Ialpha gene associates with expression of HIF-I alpha protein in breast cancer. Oncol Rep 2008, 20(5): I |8I- I I87.

16. Horree N, Groot AJ, Van Hattem WA, Heintz AP, Vooijs M, Van Diest PJ: HIF-IA gene mutations associated with higher microvessel density in endometrial carcinomas. Histopathology 2008, 52(5):637-639.

17. Konac E, Onen HI, Metindir J, Alp E, Biri AA, Ekmekci A: An investigation of relationships between hypoxia-inducible factor-I alpha gene polymorphisms and ovarian, cervical and endometrial cancers. Cancer Detect Prev 2007, 3 I (2): I02-109.

18. Fransen K, Fenech M, Fredrikson M, Dabrosin C, Soderkvist P: Association between ulcerative growth and hypoxia inducible factor-I alpha polymorphisms in colorectal cancer patients. $\mathrm{Mol}$ Carcinog 2006, 45( I I):833-840.

19. Kuwai T, Kitadai Y, Tanaka S, Kuroda T, Ochiumi T, Matsumura S, Oue N, Yasui W, Kaneyasu M, Tanimoto K, Nishiyama M, Chayama $\mathrm{K}$ : Single nucleotide polymorphism in the hypoxia-inducible factor-Ialpha gene in colorectal carcinoma. Oncol Rep 2004, I 2(5): 1033-1037.

20. Ollerenshaw M, Page T, Hammonds J, Demaine A: Polymorphisms in the hypoxia inducible factor-Ialpha gene (HIFIA) are associated with the renal cell carcinoma phenotype. Cancer Genet Cytogenet 2004, 1 53(2): 122-126.

21. Clifford SC, Astuti D, Hooper L, Maxwell PH, Ratcliffe PJ, Maher ER: The pVHL-associated SCF ubiquitin ligase complex: Molecular genetic analysis of elongin B and C, RbxI and HIF-I $\alpha$ in renal cell carcinoma. Oncogene 200I, 20:5067-5074.

22. Ling TS, Shi RH, Zhang GX, Zhu H, Yu LZ, Ding XF: Common single nucleotide polymorphism of hypoxia-inducible factor-I alpha and its impact on the clinicopathological features of esophageal squamous cell carcinoma. Chin J Dig Dis 2005, 6(4): $155-158$ 
23. Thakkinstian A, McElduff P, D'Este C, Duffy D, Attia J: A method for meta-analysis of molecular association studies. Stat Med 2005, 24(9): $1291-1306$

24. Egger M, Davey Smith G, Schneider M, Minder C: Bias in metaanalysis detected by a simples, graphical test. BMJ 1997, 3 15:629-634.

25. Bax L, Yu LM, Ikeda N, Tsuruta H, Moons KGM: Development and validation of MIX: comprehensive free software for metaanalysis of causal research data. BMC Med Res Methodol 2006, 6:50.

26. Bax L, Yu LM, lkeda N, Tsuruta H, Moons KGM: MIX: comprehensive free software for meta-analysis of causal research data. Version 1.7. 2008 [http://mix-for-meta-analysis.info].

27. Yong D, QingQing W, Hua L: Association of uteroglobin G38A polymorphism with IgA nephropathy: a meta-analysis. $\mathrm{Am} J$ Kidney Dis 2006, 48(I): I-7.

28. Kazi AA, Jones JM, Koos RD: Chromatin immunoprecipitation analysis of gene expression in the rat uterus in vivo: estrogen-induced recruitment of both estrogen receptor alpha and hypoxia-inducible factor I to the vascular endothelial growth factor promoter. Mol Endocrinol 2005, 19(8):2006-2019.

29. Hua K, Din J, Cao Q, Feng W, Zhang Y, Yao L, Huang Y, Zhao Y, Feng $Y$ : Estrogen and progestin regulate HIF-I alpha expression in ovarian cancer cell lines via the activation of Akt signaling transduction pathway. Oncol Rep 2009, 2 I (4):893-898.

Publish with Bio Med Central and every scientist can read your work free of charge

"BioMed Central will be the most significant development for disseminating the results of biomedical research in our lifetime. "

Sir Paul Nurse, Cancer Research UK

Your research papers will be:

- available free of charge to the entire biomedical community

- peer reviewed and published immediately upon acceptance

- cited in PubMed and archived on PubMed Central

- yours - you keep the copyright 